American Journal of Applied Sciences 7 (4): 486-492, 2010

ISSN 1546-9239

(c) 2010Science Publications

\title{
A New Approach in Individual Tree Counting of Nyatoh (Palaquium spp.) Using an Airborne Spectroradiometer
}

\author{
Kamaruzaman Jusoff \\ Tropical Forest Airborne Observatory (TropAIR), Faculty of Forestry, Universiti Putra Malaysia, \\ 43400 Serdang, Selangor. Malaysia
}

\begin{abstract}
Problem statement: In Malaysia inadequate data are available to make decisions regarding the sustainable management of Nyatoh (Palaquium spp.). Factual data and estimation of Nyatoh in the lowland dipterocarp forest resources are still lacking or, if available, are not complete, reliable or up to date. The collection and compilation of information and updating of existing data in near real time is a priority. Nyatoh is one of the important and popular timber species for furniture, solid doors and planks. Approach: In order to determine Nyatoh's latest species count in the Federal Territory (FT)'s Permanent Reserved Forest, a study on the distribution of Nyatoh in Bukit Nanas Forest Reserve (FR), FT was conducted using an airborne hyperspectral remote sensing technique with an objective to identify, count and map the species of Nyatoh in Bukit Nanas FR, FT. A False Color Composite (FCC) airborne hyperspectral image of the study area was used with a Sobel $3 \times 3$ filter and Spectral Angle Mapper (SAM) to classify and separated the individual Nyatoh from other tree species within Bukit Nanas FR. Results: A thematic map of individual Nyatoh spatial distribution in Bukit Nanas FR was developed showing a total of 36 individual Nyatoh trees in a $2.7 \mathrm{~h}$ study plot. There were 34 trees confirmed available on the ground with a mapping accuracy of $94.4 \%$. Conclusion: The AISA airborne spectroradiometer data is capable of mapping and counting individual tropical timber trees especially Palaquium spp. with an acceptable accuracy of more than $90 \%$. However, in order to improve the mapping accuracy, it is recommended that a higher spatial resolution image data is necessary in addition to a higher precision field GPS usage. This approach may be well integrated in the GIS-based decision support system to better manage and conserve such depleting timber species in the FT's state land and permanent reserved forests.
\end{abstract}

Key words: Nyatoh (Palaquium spp.), species count, tree mapping, airborne spectroradiometer, spectral signature

\section{INTRODUCTION}

Forest mapping and timber inventory of the mixed dipterocarp forests is one of the major applications for Malaysia's new airborne hyperspectral sensor. Airborne hyperspectral remote sensing can provide forest information products for applications in forest inventory, forest chemistry and for some Kyoto Protocol information products. Through several projects, it has been demonstrated that airborne hyperspectral sensing can provide accurate maps of hill and mountain mixed dipterocarp individual forest species (Jusoff, 2006; 2007; 2008a; 2008b). High correlations have been demonstrated between field measurements of the image versus field spectra estimates derived from hyperspectral sensing (Jusoff, 2008c; 2009a, 2009b, 2009c; 2009d; Jusoff et al., 2009; Mohd Hasmadi et al., 2010; Jusoff et al., 2010). Data for these experiments have included the UPM's-AISA data for different applications (Jusoff and Pathan, 2009; Jusoff, 2009a; 2009b; 2009c; 2009d; 2009e; Jusoff and Yusoff, 2009). To achieve operational accuracies of $90 \%$ or better for individual tropical forest species classification, it is essential that the airborne hyperspectral data are well calibrated and tested over several test sites in Malaysia. This study will report on the latest research state of airborne hyperspectral sensing of a mixed dipterocarp lowland forests in Bukit Nanas forest reserve, federal territory, Kuala Lumpur and present the airborne hyperspectral sensor approaches needed for such timber inventory at the species level applications.

Forest inventory information is obtained by measuring and assessing the trees and various characteristics of the forest. The information may be obtained from measurements taken on the ground or on remotely sensed imagery. When the measurements are taken for the entire forest, the inventory is a complete 
or $100 \%$ inventory. When the measurements are taken for a sample of the forest, for example just to locate Nyatoh trees (Palaquium spp.) in a particular forest area, it is a sampling inventory.

Nyatoh is one of the important and popular timber species for furniture, solid doors and planks in Malaysia. The seeds contain fat that can be used to manufacture candles and soap. Nyatoh wood is much sought after by the people as it is durable and suitable for making furniture. Nowadays, there are hardly Nyatoh trees to be seen in the forest as this species is few in numbers due to the illegal logging. The average domestic price of logs as in April 2007 for Nyatoh was RM $750 \mathrm{~m}^{-3}$. Meanwhile, the prices for sawntimber in category of General Market Specification (GMS) size (25-50×150 mm), strips an d scantlings are 1370,810 and RM 1450 respectively.

Airborne hyperspectral imagery has addressed some of the common issues in forestry such as the increased need and demand for forestry management and species classification. One of the uniqueness of such sensor is its high spectral and spatial resolution. This provides precise classification of individual tree at a species level within a forest, which allows the user to detect and record the makeup of its timber volume estimates due to the different spectral signatures registered by different individual species. Timber inventory assessments seems to be improved using airborne hyperspectral imagery seems, allowing for increased accuracy and detail of individual species for sustainable development and forest statistics (Jusoff, 2006). The general objective of this study is therefore to assess the capability of an airborne spectroradiometer AISA data for individual species mapping and timber volume estimation. The specific objective is to identify, quantify and map the Nyatoh trees at a species level in Bukit Nanas FR, Federal Territory (FT), Kuala Lumpur, Malaysia.

\section{MATERIALS AND METHODS}

Description of study site: Bukit Nanas FR or 'Pineapple Hill' is located in Bukit Nanas, Kuala Lumpur with latitude of 3.1518 or $3^{\circ} 96$ and longitude of 101.7022 or $101^{\circ} 427$ (Fig. 1). It covers an area of approximately 11 ha and is the only remaining virgin tropical rainforest in the heart of the city of Kuala Lumpur. This forest which is located in the city centre in between Jalan Ampang and Jalan Raja Chulan helps to cleanse the air of its surrounding environment by acting as a purifier for dust and toxic pollutants. Bukit Nanas FR is a lowland dipterocarp forest where the most frequent emergent species includes Shorea bracteolata, Dipterocarpus baudii and Dyera costulata (Putz, 1978).

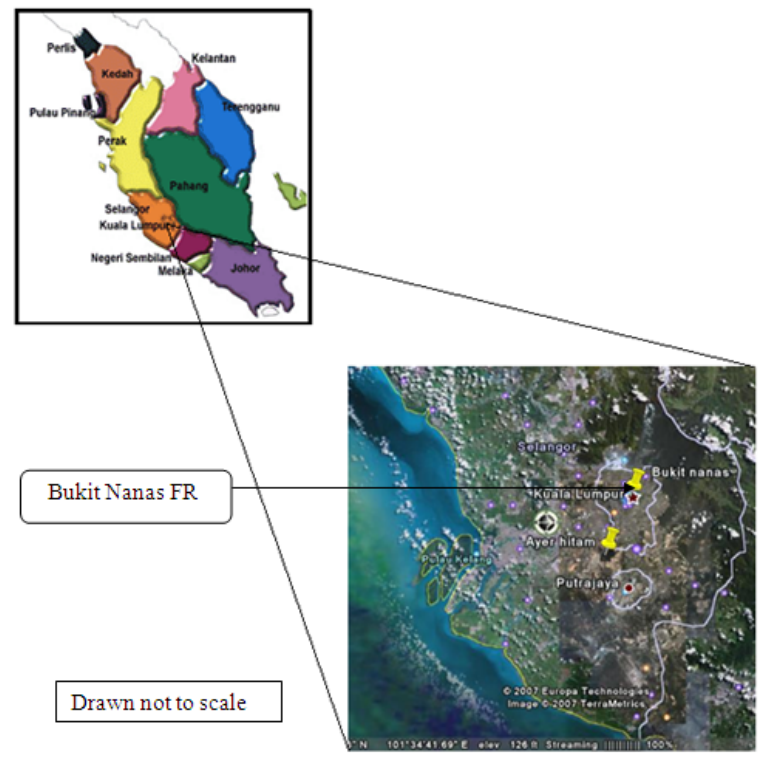

Fig. 1: A map of Peninsular Malaysia showing the study area

This forest is situated at the height of $300 \mathrm{~m}$ above the sea level. On the other hand, this forest acts as "forest lung" in the city of Kuala Lumpur. The rich variety of flora that flourishes within the forest includes rare herbs, creepers, ferns, climbers and giant bamboo grasses. These 10.5 ha forest reserve is initially home to the Malaysian tigers. Also, monkeys, pythons, squirrels and monitor lizards can still be seen in this forest reserve. Besides that, there are jungle trails, a visitor's centre and birds watching area, huts, lookout platform and a forestry museum in this forest reserve. Bukit Nanas or formerly known as Bucket Weld FR was gazetted as a forest reserve in 1906. Meanwhile, in 1934, this forest reserve was gazetted as Wildlife Reserve and Bird Sanctuary. In 1950, an untouched area of about 5 ha was designated as Virgin Jungle Reserve. It was believed that this forest is over 3 million years old.

The climate of Bukit Nanas FR is humid and hot in the whole year with a mean daily temperature of $27^{\circ} \mathrm{C}$. The hot and humid climate of Bukit Nanas FR is accompanied by an average rainfall of 2,500 mm (100 inches) annually with the highest of $290 \mathrm{~mm}$ per month and the lowest at $130 \mathrm{~mm}$ per month with a high humidity level at $80 \%$ throughout the year.

Methodology: The image of this study was acquired using an airborne spectradiometer sensor on March 2007 at the altitude of $1000 \mathrm{~m}$ above sea level with a spatial resolution of $1 \mathrm{~m}^{2}$. The raw data was pre- 
processed on-board using a Caligeo software, which is a plug-in of the latest ENVI 4.2 to reduce the unwanted effects, especially to correct for sensor-and platformspecific radiometric and geometric distortions of data. Thus, the quality of the image data for subsequent advance processing will be better enhanced.

Image enhancement which comprise of contrast enhancement and band combination was performed to enhance the clarity of the image in order to obtain a more accurate classification of Nyatoh. Contrast enhancement was conducted to expand the original brightness of the image while band combination enables images can be recorded and displayed in color or black and white. Supervised image classification was later used to classify the image into predetermined species class using the spectra from the Regions Of Interest (ROIs) and extract the quantitative information from remote sensed image data. Minimum distance algorithm was used to perform classification where it uses the mean vectors of each extracted spectra and calculates the Euclidean distance from each unknown pixel to the mean vector for each classes. All pixels are classified to the nearest class unless a standard deviation or distance threshold is specified, in which case some pixels may be unclassified if they do not meet the selected criteria. Minimum distance algorithm was selected to perform classification on the image because it can produce most reasonable classification among other supervised classification algorithms. Besides, it is also mathematically simple and computation efficient in sense of the classification can be done to a large area within a short period of time. Sieving and clumping technique were conducted after supervised classification. The function of sieving is to remove the isolated classified pixels in classification images using blob grouping. The sieve classes methods looks at the neighboring 4 or 8 pixels to determine that pixel is grouped with pixels of the same class. The number of pixels in a class that were grouped less than the value was removed from the class. When pixels were removed from a class using sieving, black pixels which are unclassified were left. Classified images usually faced some problems such as the lack of spatial coherency liked speckle or holes in the classified areas. Low pass filtering was later used to smooth these images, but the class information was contaminated by adjacent class codes. The selected classes were clumped together by first performing a dilate operation and then an erode operation on the classified image using a kernel of the size specified in the parameters dialogue.

Ground verification was performed to verify and match the Nyatoh trees identified from the image versus the field spectra archived data. It was executed by taking the exact GPS location of the Nyatoh trees on the ground to assess the mapping accuracy of the individual Nyatoh trees identified from the image spectra. The data was collected in the form of latitude and longitude of the position of the Nyatoh trees in Bukit Nanas FR using a handheld GPS. After the data was verified, an accuracy assessment was conducted based on the ground truth to determine the degree of mapping confidence achieved. The formula for calculating the accuracy can be given as:

$$
\begin{aligned}
\operatorname{Accuracy}(\%) & =100 \%-\text { Error }(\%) \\
& =100 \%-\frac{\text { No.of incorrect Karas tree verifed }}{\text { Total no trees selectedformimage }} \times 100 \%
\end{aligned}
$$

The outcome of this study is the development of a thematic map showing the gospatial distribution of Nyatoh in Bukit Nanas FR based on airborne sensing technique. Once the individual trees of Nyatoh can be easily located and mapped in an acceptable precision, tree tagging map of Nyatoh can then be further developed showing precisely their specific locations in the area of interest under study. This information will definitely assist in the development of a management and conservation plan for the future sustainable development to avoid alarming depletion of Nyatoh population in the FT of Kuala Lumpur.

\section{RESULTS}

In this study, band 12, 16, 20 (RGB) with a linear stretch was selected to be the best combinations. At the same time, it was adopted for further analysis in the image classification since it provides a well enhanced color composite image with respect to the forest cover (Mohd Hasmadi et al., 2010; Jusoff et al., 2010; Jusoff, 2009e; Jusoff and Ibrahim, 2009). Meanwhile, a Sobel filter $3 \times 3$ was found to be the most appropriate for visual interpretation of Nyatoh on the image (Fig. 2).

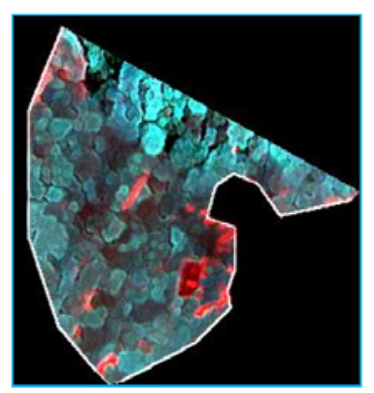

Fig. 2: False color composite of band combination 1216-20 (RGB) with Sobel Filter $(3 \times 3)$ 


\section{DISCUSSION}

A similar filter was also reported best used for other applications such as in mapping power transmission lines and Search-and-Rescue for missing aircraft (Jusoff and Yaacob, 2008;
Jusoff, 2007; 2008b; 2010). On the other hand, the end member spectra of Nyatoh used by SAM were obtained from the archived spectral library using a handheld specroradiometer. The image spectra of Nyatoh obtained from the airborne data is shown in Fig. 3.

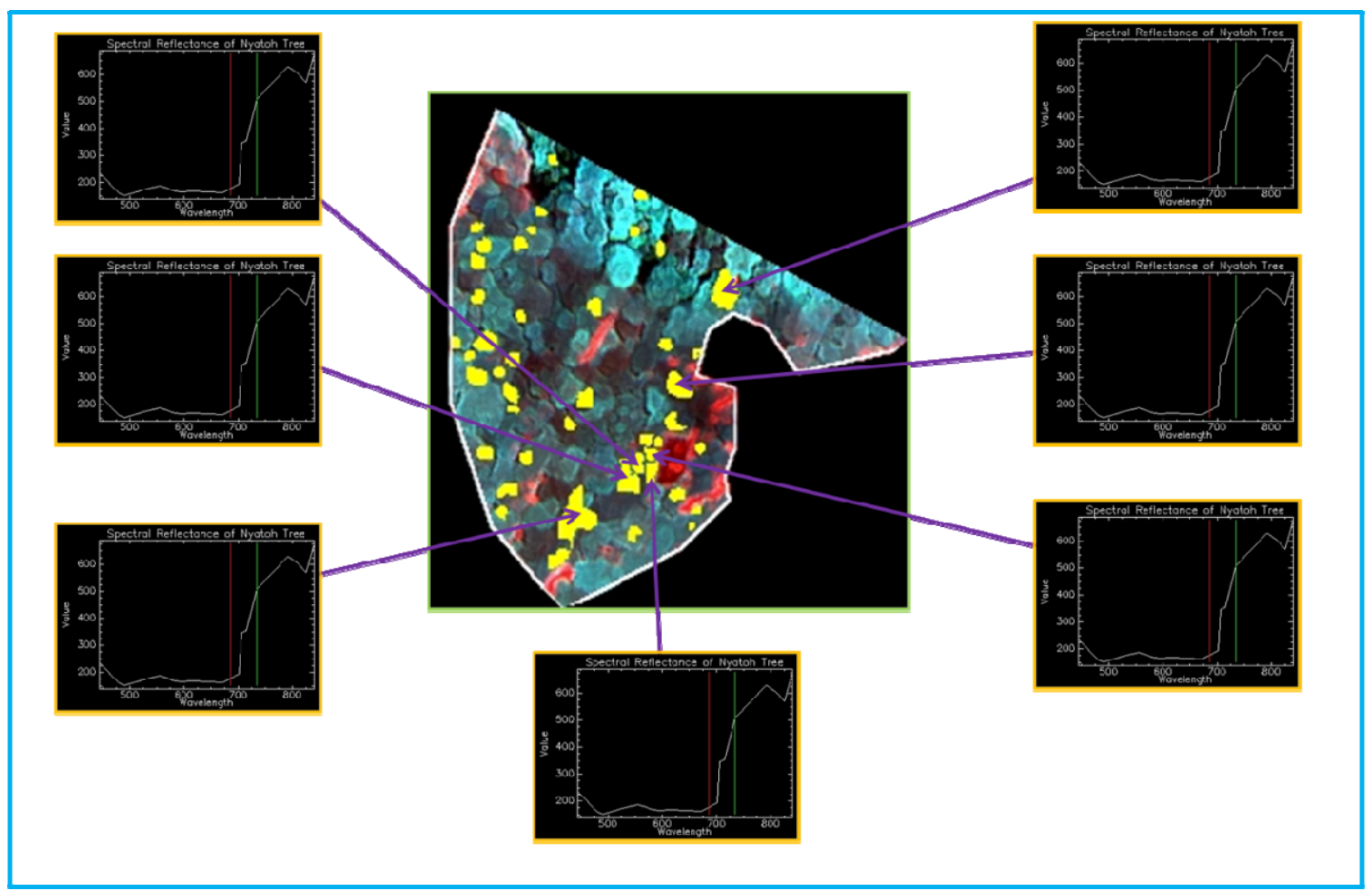

Fig. 3: The development of some selected image spectral reflectance library of Nyatoh in the study area

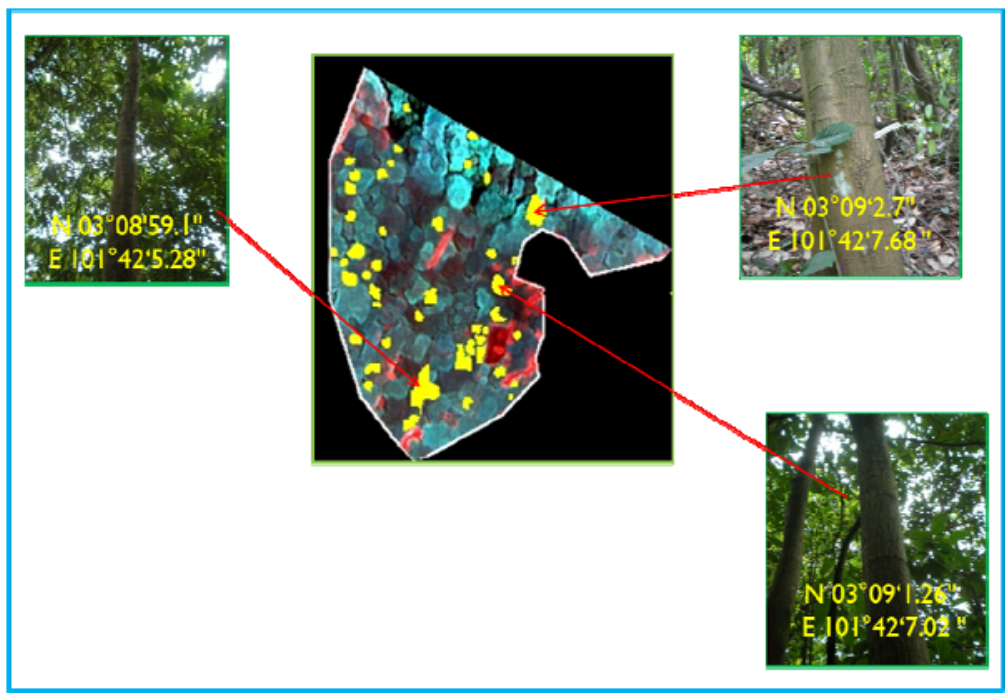

Fig. 4a: Location of some selected Nyatoh trees as verified from ground checks 
Am. J. Applied Sci., 7 (4): 486-492, 2010

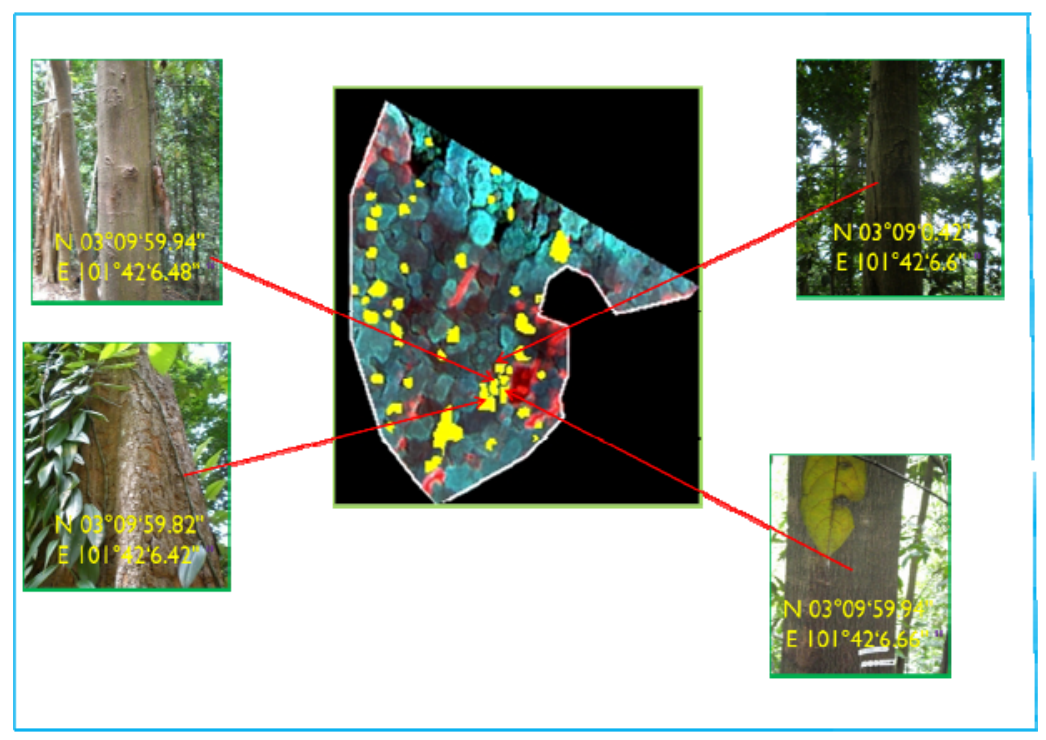

Fig. 4b: Location of some selected Nyatoh trees as verified from ground checks

Table 1: The GPS coordinates of Nyatoh trees as mapped from the airborne sensor

\begin{tabular}{|c|c|c|}
\hline Trees & Latitude & Longitude \\
\hline 1 & N 0308’58.500”' & E $101^{\circ} 42^{\prime} 5.10^{\prime \prime}$ \\
\hline 2 & N 0308’58.910" & Е $101^{\circ} 42^{\prime} 6.35^{\prime \prime}$ \\
\hline 3 & N 0308’59.100” & E $101^{\circ} 42^{\prime} 5.28^{\prime \prime}$ \\
\hline 4 & N 0308’59.820” & Е $101^{\circ} 42^{\prime} 6.42^{\prime \prime}$ \\
\hline 5 & N 0308'59.940"' & E $101^{\circ} 42^{\prime} 6.48^{\prime \prime}$ \\
\hline 6 & N 0308'59.940"' & Е $101^{\circ} 42^{\prime} 6.66^{\prime \prime}$ \\
\hline 7 & N 0309'0.2400" & Е $101^{\circ} 42^{\prime} 6.72^{\prime \prime}$ \\
\hline 8 & N $03^{\circ} 09^{\prime} 0.3600^{\prime \prime}$ & Е $101^{\circ} 42^{\prime} 6.78^{\prime \prime}$ \\
\hline 9 & N 0309'0.4200"' & E $101^{\circ} 42^{\prime} 6.60^{\prime \prime}$ \\
\hline 10 & N 0309’0.6600" & E $101^{\circ} 42^{\prime} 5.40^{\prime \prime}$ \\
\hline 11 & N $03^{\circ} 09^{\prime} 0.7800^{\prime \prime}$ & E $101^{\circ} 42^{\prime} 7.02^{\prime \prime}$ \\
\hline 12 & N 0309'1.0800"' & Е $101^{\circ} 42^{\prime} 5.58^{\prime \prime}$ \\
\hline 13 & N 0309'1.2600" & Е $101^{\circ} 42^{\prime} 7.02^{\prime \prime}$ \\
\hline 14 & N 0309'2.7”00 & Е $101^{\circ} 42^{\prime} 7.68^{\prime \prime}$ \\
\hline 15 & N 03º9'1.9700 & Е $101^{\circ} 42^{\prime} 6.91$ \\
\hline 16 & N 03ํㅇ' 1.8000 & E $101^{\circ} 42^{\prime} 7.43$ \\
\hline 17 & $\mathrm{~N} 03^{\circ} 09^{\prime} 0.2800$ & E $101^{\circ} 42^{\prime} 7.42$ \\
\hline 18 & 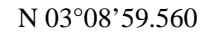 & E $101^{\circ} 42^{\prime} 7.10$ \\
\hline 19 & N 030'ㅇ․ 300 & Е $101^{\circ} 42^{\prime} 7.39$ \\
\hline 20 & N $03^{\circ} 08^{\prime} 59.040$ & Е $101^{\circ} 42^{\prime} 7.29$ \\
\hline 21 & N 03º8'59.210 & E $101^{\circ} 42^{\prime} 4.86$ \\
\hline 22 & N 0309’0.1500 & E $101^{\circ} 42^{\prime} 4.67$ \\
\hline 23 & $\mathrm{~N} 03^{\circ} 09^{\prime} 0.2500$ & E $101^{\circ} 42^{\prime} 4.02$ \\
\hline 24 & N 03º9'1.1900 & E $101^{\circ} 42^{\prime} 4.48$ \\
\hline 25 & $\mathrm{~N} 03^{\circ} 09^{\prime} 0.9300$ & E $101^{\circ} 42^{\prime} 4.48$ \\
\hline 26 & N 03º9'1.4900 & E $101^{\circ} 42^{\prime} 4.25$ \\
\hline 27 & N 03º9'1.5200 & E $101^{\circ} 42^{\prime} 3.87$ \\
\hline 28 & $\mathrm{~N} 03^{\circ} 09^{\prime} 1.7800$ & E $101^{\circ} 42^{\prime} 3.80$ \\
\hline 29 & N 03ํํ' 1.9800 & E $101^{\circ} 42^{\prime} 3.58$ \\
\hline 30 & 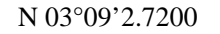 & E $101^{\circ} 42^{\prime} 3.90$ \\
\hline 31 & N 03º9’3.2800 & E $101^{\circ} 42^{\prime} 3.87$ \\
\hline 32 & N 030.'3.5400 & E $101^{\circ} 42^{\prime} 4.33$ \\
\hline 33 & N 0309’3.8000 & Е $101^{\circ} 42^{\prime} 4.75$ \\
\hline 34 & 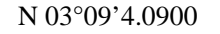 & E $101^{\circ} 42^{\prime} 4.91$ \\
\hline 35 & 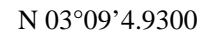 & E $101^{\circ} 42^{\prime} 5.14$ \\
\hline 36 & N $03^{\circ} 09^{\prime} 4.3800$ & E $101^{\circ} 42^{\prime} 6.43$ \\
\hline
\end{tabular}

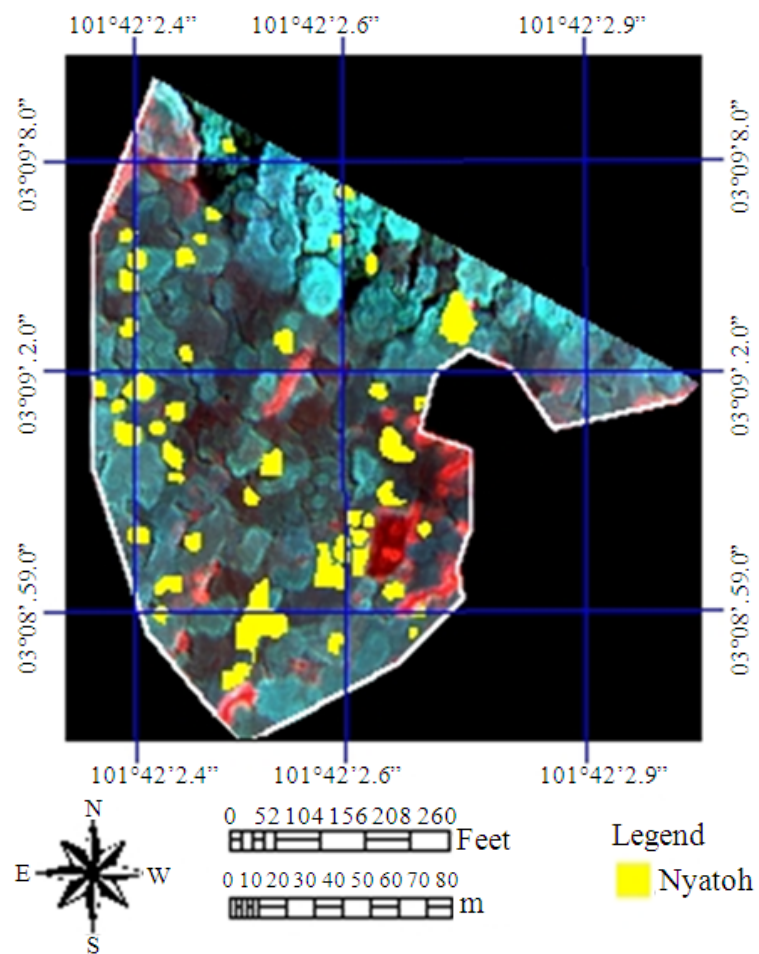

Fig. 5: Thematic map of Nyatoh distribution in Bukit Nanas FR

The 0.15 radian used in this study was the most suitable and selected to classify and extract the individual Nyatoh trees from the forest. Pixels with an angle larger than this value were not classified. By 
referring to the image, features such as the forest gap and other tree species can be easily differentiated from the Nyatoh trees. The precise location of Nyatoh trees is difficult to be identified since it is too scattered and not grouped together. Therefore, the post classification which composed of clumping and sieving techniques was required to minimize this positioning issue. Table 1 showed the GPS locations of Nyatoh trees identified from the image and verified on the ground by the field survey team. From a total number of 36 trees identified from the imagery, 34 Nyatoh trees were ground verified and confirmed correct by the field survey team with the mapping accuracy of $94.4 \%$. Some selected samples of Nyatoh found in Bukit Nanas FR are shown in Fig. 4a and b.

Finally, the TropAIRMap ${ }^{\mathrm{TM}}$ product of Nyatoh spatial distribution in Bukit Nanas FR was produced as indicated by the yellow spots in the image (Fig. 5). With this geospatial thematic map, a tree tagging map specifically for Nyatoh can be further developed. This geospatial map is also useful to gather the actual number of Nyatoh trees left behind in the whole forest of FT, Kuala Lumpur if the airborne flight mission covers the whole FT airspace in the future.

\section{CONCLUSION}

An airborne spectroradiometer is capable of mapping 36 individual Nyatoh trees in the study plot of 2.7 ha in Bukit Nanas FR. with a mapping accuracy of 94.4\%. Further research should be focused on identifying Nyatoh species using a higher spatial resolution to improve the mapping classification accuracy. Being the airborne spectroradiometer data a "ready-made GIS", Nyatoh trees can be well managed and conserved in the FT State land and Permanent Reserved Forests if a GIS-based geospatial database of Nyatoh can be developed in the near future.

\section{ACKNOWLEDGEMENT}

My warmest thanks are also due to Peninsular Malaysia Forestry Department HQ (FDHQ) for the permission to allow Bukit Nanas FR as the study site.

\section{REFERENCES}

Jusoff, K. and K. Ibrahim, 2009. Hyperspectral remote sensing for tropical rainforest. Am. J. Applied Sci., 6: 2001-2005.

Jusoff, K. and M.H.M. Yusoff, 2009. New approaches in estimating rubberwood standing timber volume using airborne hyperspectral sensing. J. Modern Applied Sci., 3: 62-70.
Jusoff, K. and M. Pathan, 2009. Mapping of individual oil palm trees using airborne hyperspectral sensing: An overview. Applied Phys. Res., 1: 15-30.

Jusoff, H.K. and N. Yaacob, 2008. Mapping of power transmission lines on Malaysian highways using UPM-APSB's AISA airborne hyperspectral imaging system. J. Comput. Inform. Sci. 1: 88-94.

Jusoff, K., 2006. Individual mangrove species identification and mapping in Port Klang using airborne hyperspectral imaging. J. Sustain. Sci. Manage., 1: 27-36.

Jusoff, K., 2007. Advanced processing of UPMAPSB's AISAairborne hyperspectral images for individual timber species identification and mapping. Int. J. Syst. Appl. Eng. Dev., 2: 21-26.

Jusoff, K., 2008a. Development of geographic information system database for town planning of Sri Serdang, Malaysia using UPM-APSB's AISA airborne hyperspectral imaging data. The National Mapping and Spatial Data Committee (JPDSN), Malaysian National Survey and Mapping Department. Bulletin GIS, pp: 1-22.

Jusoff, K., 2008b. Search-and-Rescue (SAR) operations for the missing Bell 206 long ranger helicopter in Sarawak, Malaysia using near real-time airborne hyperspectral imaging systems. Disaster Prev. Manage. Int. J., 7: 94-103.

Jusoff, K., 2008c. Geospatial information technology for conservation of coastal forest and mangroves environment in Malaysia. Comput. Inform. Sci., 1: 129-134.

Jusoff, K.H., 2009a. Mapping of sabah islands using airborne hyperspectrometer. J. Geogr. Geol., 1: 2-6.

Jusoff, K., 2009b. Precision forestry using airborne hyperspectral imaging sensor. J. Agric. Sci., 1: $142-147$.

Jusoff. K., 2009c. Sustainable management of matured oil palm plantation in UPM campus, Malaysia using airborne remote sensing. J. Sustain. Dev., 2: $195-200$.

Jusoff, K., 2009d. Land use and cover mapping with airborne hyperspectral imager in situ, Malaysia. J. Agric. Sci., 1: 120-131.

Jusoff, K., 2009e. Airborne hyperspectral sensor for individual species counting and mapping of Karas (Aquilaria malaccensis) in Bukit Nanas FR, Malaysia. World Applied Sci. J., 7: 1246-1251.

Jusoff, H.K., 2010. Pixel-based airborne hyperspectral sensing technique for search-and-rescue of the missing RMAF NURI helicopter in GentingSempah, Malaysia. J. Disaster Prev. Manage., 19: 87-101.

Jusoff, K., M.H. Ismail and N.M.H. Ali, 2009. Spectral separability of tropical forest tree species using airborne hyperspectral imager. J. Environ. Sci. Eng., 3: 37-41. 
Jusoff, H.K., H.M.M. Yusoff and N.H.M. Ali, 2010. Spectral signatures of leaf fall diseases in Hevea brasiliensis using a handheld spectroradiometer. J. Modern Applied Sci., 4: 78-84.

Mohd Hasmadi, I., J. Kamaruzaman and M.A. Nurul Hidayah, 2010. Analysis of crown spectral characteristic and tree species mapping of tropical forest using hyperspectral imaging. J. Trop. Fore. Sci., 22: 67-73.
Putz, F.E., 1978. A survey of virgin jungle reserves in Peninsular Malaysia. Forest Research Institute Research Pamphlet No. 73. Department of Forestry, Peninsular Malaysia, Kuala Lumpur, pp: 87. 